\title{
Non-covalent conjugates of single-walled carbon nanotubes and folic acid for interaction with cells overexpressing folate receptors
}

Castillo, John J. ; Rindzevicius, Tomas; Novoa, Leidy V. ; Svendsen, Winnie Edith; Rozlosnik, Noemi; Boisen, Anja; Escobar, Patricia ; Martínez, Fernando ; Castillo-Léon, Jaime

Published in:

Journal of Materials Chemistry B

Link to article, DOI:

$10.1039 / \mathrm{c} 2 \mathrm{tb} 00434 \mathrm{~h}$

Publication date:

2013

Document Version

Publisher's PDF, also known as Version of record

Link back to DTU Orbit

Citation $(A P A)$ :

Castillo, J. J., Rindzevicius, T., Novoa, L. V., Svendsen, W. E., Rozlosnik, N., Boisen, A., Escobar, P., Martínez, F., \& Castillo-Léon, J. (2013). Non-covalent conjugates of single-walled carbon nanotubes and folic acid for interaction with cells overexpressing folate receptors. Journal of Materials Chemistry B, 1(10), 1475-1481. https://doi.org/10.1039/c2tb00434h

\section{General rights}

Copyright and moral rights for the publications made accessible in the public portal are retained by the authors and/or other copyright owners and it is a condition of accessing publications that users recognise and abide by the legal requirements associated with these rights.

- Users may download and print one copy of any publication from the public portal for the purpose of private study or research.

- You may not further distribute the material or use it for any profit-making activity or commercial gain

- You may freely distribute the URL identifying the publication in the public portal 


\section{Journal of \\ Materials Chemistry B}

RSCPublishing

\section{PAPER}

Cite this: I Mater Chem. B, 2013, 1, 1475

Received 19th November 2012

Accepted 4th January 2013

DOI: $10.1039 / \mathrm{c} 2 \mathrm{tb} 00434 \mathrm{~h}$

www.rsc.org/MaterialsB

\section{Non-covalent conjugates of single-walled carbon nanotubes and folic acid for interaction with cells over- expressing folate receptors $t$}

\author{
John J. Castillo, ${ }^{a}$ Tomas Rindzevicius, ${ }^{\mathrm{b}}$ Leidy V. Novoa, ${ }^{\mathrm{C}}$ Winnie E. Svendsen, ${ }^{\mathrm{b}}$ \\ Noemi Rozlosnik, ${ }^{\mathrm{b}}$ Anja Boisen, ${ }^{\mathrm{b}}$ Patricia Escobar, ${ }^{\mathrm{c}}$ Fernando Martínez ${ }^{\mathrm{a}}$ \\ and Jaime Castillo-León*b
}

We here present a method to form a noncovalent conjugate of single-walled carbon nanotubes and folic acid aimed to interact with cells over-expressing folate receptors. The bonding was obtained without covalent chemical functionalization using a simple, rapid "one pot" synthesis method. The zeta potential for the single-walled carbon nanotube-folic acid solution was $-32.4 \mathrm{mV}$ at $\mathrm{pH} 7.0$ and the result indicates that the folic acid coating inhibited aggregation of the carbon nanotubes. Properties of the single-walled carbon nanotube-folic acid conjugate were analyzed using ultraviolet-visible, fluorescence and Raman spectroscopies. While the folic acid fluorescence signature was significantly quenched by the presence of single-walled carbon nanotubes, the Raman spectra of the conjugate displayed a decreased distribution of $\mathrm{sp}^{3}$ sites. Both results were attributed to the noncovalent functionalization of the single-walled carbon nanotubes with folic acid. A more detailed investigation of the single-walled carbon nanotube-folic acid conjugates utilizing scanning electron microscopy, atomic force microscopy and energy-dispersive X-ray spectroscopy confirmed the presence of the well-defined folic acid coating on the individual single-walled carbon nanotubes. The single-walled carbon nanotube-folic acid conjugates were incubated with THP-1 cells and the internalization was evaluated by Giemsa staining with light microscopy, and cytotoxicity was evaluated using the MTT reduction assay. The cytotoxicity studies presented a low toxicity of the conjugates in the THP-1 cells. The low toxicity and the cellular uptake of single-walled carbon nanotubefolic acid by cancer cells suggest their potential use in carbon nanotube-based drug delivery systems and in the diagnosis of cancer or tropical diseases such as leishmaniasis.

\section{Introduction}

Since their first discovery in 1991, carbon nanotubes (CNTs) have attracted significant attention from researchers all around the world. ${ }^{1}$ In the development of new materials with interesting biomedical properties that facilitate drug delivery in cancer therapies, ${ }^{1}$ one of the major difficulties is to functionalize CNTs with different types of biomolecules. ${ }^{2-5}$ In order to functionalize CNTs and simultaneously prevent inter-CNT aggregation, two methodologies have so far been suggested: (i) covalent and (ii) noncovalent functionalization of the CNT sidewalls. In the first strategy, several research groups have utilized the $N$-ethyl- $N^{\prime}$-(3-(dimethylamino)

${ }^{a}$ Centro de Investigaciones en Catálisis, Universidad Industrial de Santander, Sede Guatiguará UIS Km 2 vía Refugio, Piedecuesta, Colombia

${ }^{b}$ Department of Micro- and Nanotechnology, Technical University of Denmark, Lyngby 2800, Denmark.E-mail: jaic@nanotech.dtu.dk; Tel: +45 45256837

${ }^{c}$ Centro de Investigaciones en Enfermedades Tropicales, Universidad Industrial de Santander, Sede Guatiguará UIS Km 2 vía Refugio, Piedecuesta, Colombia

$†$ Electronic supplementary information (ESI) available: Interaction of SWCNT-FA with a folate receptor negative cell line. See DOI: 10.1039/c2tb00434h propyl)carbodiimide/ $N$-hydroxysuccinimide (EDC/NHS) chemistry to covalently bind biomolecules to single-walled carbon nanotubes (SWCNTs). ${ }^{6-8}$ Disadvantages of the latter approach include considerable processing times and costs. Furthermore, in covalent approaches, CNTs are mixed with strong inorganic acids at high temperatures to create carboxylic groups on the surface. ${ }^{6}$

Although this strategy has been recognized as an effective path for the solubilization and stable dispersion of CNTs, aggressive chemical modifications might introduce structural defects that produce changes in carbon hybridization from $\mathrm{sp}^{2}$ to $\mathrm{sp}^{3}$ leading to a possible partial loss of conjugation affecting the mechanical and electronic properties of CNTs. ${ }^{9}$ The modification-induced structural changes in the electronic and mechanic properties of CNTs can be minimized by using a noncovalent functionalization methodology. Sidewalls of CNTs have previously been functionalized using noncovalently bound polymers, ${ }^{10}$ proteins, $^{2}$ DNA, ${ }^{11} \pi-\pi$ stacking ${ }^{12}$ or hydrophobic interactions. ${ }^{\mathbf{1 3}}$ The noncovalent dispersion procedures usually involve ultrasonication, centrifugation and filtration process steps. ${ }^{9}$ 
Folic acid (FA) is an attractive ligand that can be used to target cell membranes. ${ }^{14,15}$ The high affinity between FA and folate receptors (FRs) suggests the use of FA as a key target in the construction of CNT-based drug delivery nanosystems. ${ }^{15}$ In previous reports, FA-functionalized CNTs have been produced using covalent links. ${ }^{8}$ Kang and co-workers, ${ }^{14}$ who studied the intracellular trafficking and uptake of CNT-FA in Hep G2 cells, functionalized CNT with FA via EDC/NHS chemistry. In the latter report, further purification steps were necessary to eliminate excess FA, EDC and NHS. Furthermore, the toxicity of EDC was confirmed on a breast cancer cell line (MCF-7) and two leukemic cell lines (THP-1 and KG-1). ${ }^{\mathbf{1 6}}$ In a similar investigation Kam et al. ${ }^{3}$ utilized CNT-FA conjugates as a photothermal agent for selective cancer cell destruction. A covalent functionalization of CNTs was achieved using a strong mix of inorganic acids at high temperatures. Although covalent methodologies have proven to be highly stable, process difficulties associated with potentially dangerous acid conditions, long reaction times and additional purification steps have limited practical uses.

In this contribution, we present a noncovalent, rapid and facile "one pot" synthesis approach to form a conjugate between SWCNTs and FA without any further purification steps. Analysis with spectroscopic and microscopic tools showed strong evidence of chemical stability of the SWCNT-FA conjugates. The SWCNT-FA conjugate exhibited a low toxicity and it was internalized by THP-1 cells (human acute monocytic leukemia cell). The described noncovalent conjugate can specifically be applied in cancer cell therapy and for selective destruction of cells infected with parasites responsible for tropical diseases such as leishmania.

\section{Materials and methods}

\section{Materials}

SWCNTs with diameters ranging from 2 to $5 \mathrm{~nm}$ and lengths between 500 and $2000 \mathrm{~nm}$ were purchased from Unydim, California (USA). FA was obtained from Sigma-Aldrich Corp. All chemicals used in this work were of analytical grade.

\section{Synthesis of the SWCNT-FA conjugate}

$5 \mathrm{mg}$ of SWCNTs were ultrasonicated (Processor cpx 130PB Cole Parmer) for $15 \mathrm{~min}$ in $5 \mathrm{~mL}$ of a $5 \mathrm{mM}$ aqueous solution of FA. FA was dissolved in water to which was added $10 \mu \mathrm{L}$ of $\mathrm{NaOH}(1 \mathrm{M})$ due to the poor solubility of FA. FA powder $(0.011 \mathrm{~g})$ was mixed
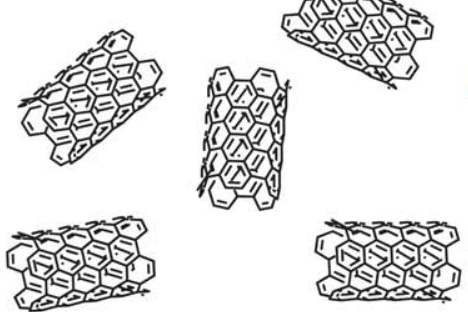

ultrasonication

$15 \mathrm{~min}$
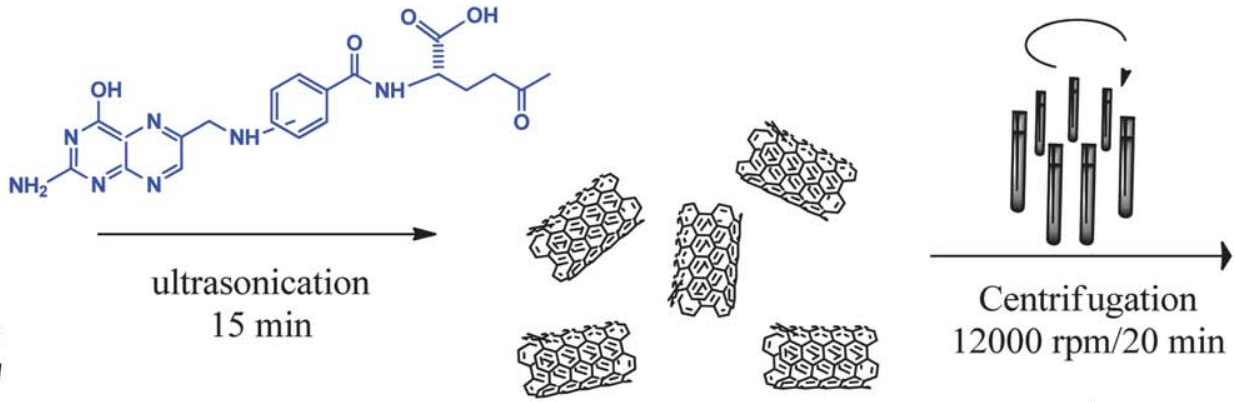

Centrifugation $12000 \mathrm{rpm} / 20 \mathrm{~min}$
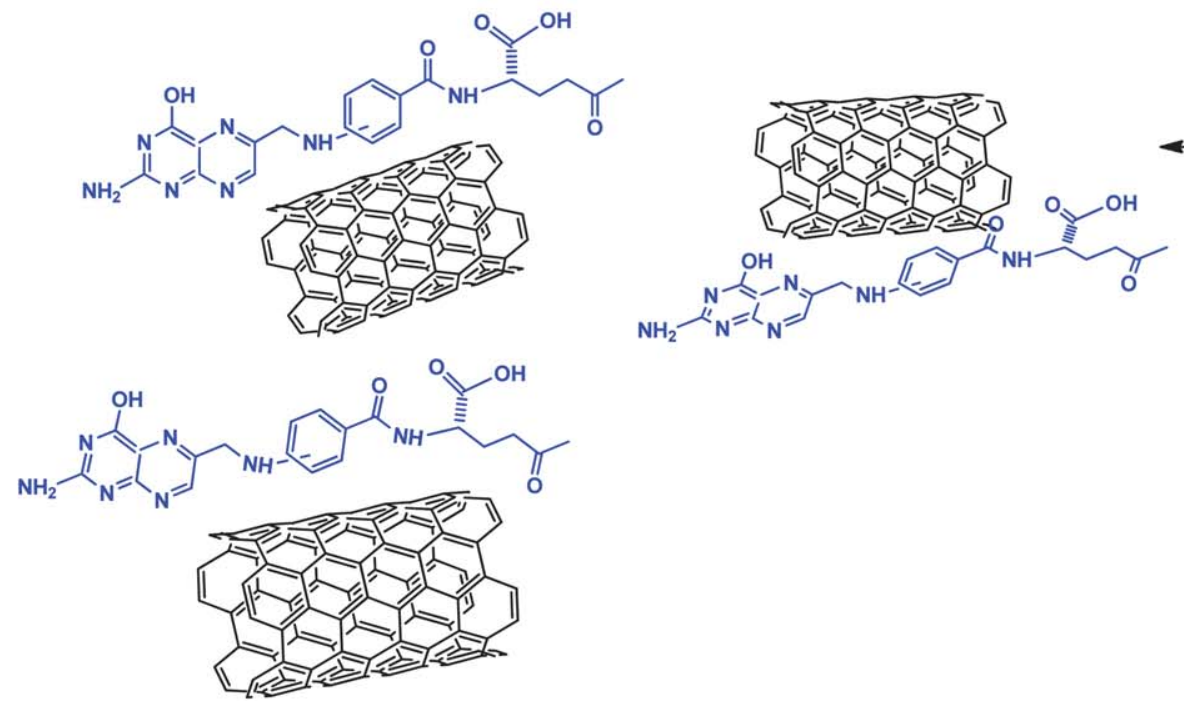

Scheme 1 Non-covalent functionalization of SWCNTs with FA. 
with water $(5 \mathrm{~mL})$ and magnetically stirred until a yellow-to-clear transition was observed. The dispersion of SWCNT-FA was centrifuged at $12000 \mathrm{rpm}$ for $20 \mathrm{~min}$. The supernatant was collected and carefully separated from the solid. After aggregation, the solution contained a large bundle of SWCNTs. The supernatant was washed with water several times and a dialysis membrane with a pore size MWCO 100000 was used to remove excess FA. Finally, the SWCNT-FA solution was stored at $4{ }^{\circ} \mathrm{C}$. A schematic illustration of the fabrication steps is shown in Scheme 1.

\section{Spectroscopic characterization and zeta potential}

Ultraviolet-visible (UV-Vis) absorption spectra were collected in a quartz cell with a $1.0 \mathrm{~cm}$ path length using an Agilent-HP 8453 spectrophotometer. The fluorescence emission from SWCNT-FA solutions was recorded using a standard Perkin Elmer LS-55 luminescence spectrophotometer with an excitation wavelength of $364 \mathrm{~nm}$. Raman experiments were performed using a Thermo Scientific DXR Raman microscope. An optical microscope was coupled to a single grating spectrometer with $5 \mathrm{~cm}^{-1}$ FWHM spectral resolution and \pm 2 wavenumber accuracy. A frequencystabilized single diode laser was operated at $780 \mathrm{~nm}$. Raman spectra were recorded using a $50 \times$ long working distance objective, $5 \mathrm{~mW}$ laser power and $10 \mathrm{~s}$ signal accumulation times.

A Zetasizer Nano particle analyzer series (Malvern, model ZEN3500) was employed to observe the dispersion state and measure the zeta potential of the SWCNT-FA conjugate. The scanning electron microscopy (SEM) and energy-dispersive X-ray spectroscopy (EDX) analyses were performed using a Quanta FEG SEM microscope with an EDX detector (Oregon, USA). All atomic force microscopy (AFM) images were recorded using an XE-150 Premier cross-functional AFM (Park Systems, Korea) with a PPPNVHR AFM probe (Nanosensors, Switzerland).

\section{In vitro assessment of cytotoxicity}

Transformed THP-1 cells were incubated with stock solutions of SWCNT-FA previously incubated with the RPMI 1640 medium without FCS for 24,48 and $72 \mathrm{~h}$ at $37^{\circ} \mathrm{C}$ in a $5 \% \mathrm{CO}_{2}$ humidified atmosphere. The cell viability was evaluated by the MTT reduction assay. Miltefosine was used as a control.

\section{Cell internalization}

Transformed THP-1 cells were incubated with SWCNT-FA solutions of $0.031,0.062$ and $0.125 \mathrm{mg} \mathrm{mL}^{-1}$ for 24,48 and $72 \mathrm{~h}$, respectively. Images were photographed using a charge-coupled device (CCD) color digital camera Nikon Coolpix 5000.

\section{Results}

The dispersion between SWCNT and FA before and after the ultrasonication step is shown in Fig. 1. A homogeneous dispersion of SWCNTs was obtained after centrifugation of the nanotubes. To verify the stability of the obtained SWCNT-FA solution, the zeta potential method was used. The zeta potential is a physical property that is related to the chemical stability of colloidal dispersions and indicates the degree of repulsion

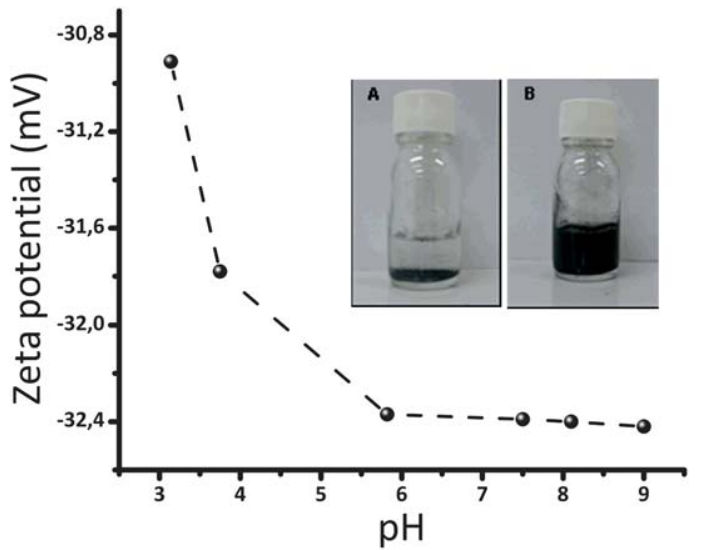

Fig. 1 The SWCNT-FA solution before (A) and after (B) the ultrasonication step. The zeta potential behaviour vs. $\mathrm{pH}$ values (C).

between adjacent, similarly charged particles in the dispersion media. ${ }^{11}$ Fig. 1 portrays the zeta potential of the SWCNT-FA solution at different $\mathrm{pH}$ values. In the $\mathrm{pH}=6-9$ interval the zeta potential exhibited only minor changes, and at $\mathrm{pH}=7.0$ the recorded value was $-32.4 \mathrm{~mW}$. This result was an indication that the SWCNT-FA conjugates formed a stable dispersion at physiologically important $\mathrm{pH}$ values and that they were applicable for biomedicine-related processes. The solubility of the SWCNT-FA conjugates was also tested in the cell culture medium used, RPMI 1640 medium supplemented with fetal bovine serum, displaying no aggregation.

In the next step, we investigated the SWCNT-FA bonding properties using UV/Vis and fluorescence spectroscopies. The UV-Vis absorbance spectra of the SWCNT-FA bio-conjugate is presented in Fig. 2. The suspension showed an absorption band at $265 \mathrm{~nm}$, which can be attributed to the absorption of tubular graphite as previously identified. ${ }^{16}$

The absorption peaks at 282 and $364 \mathrm{~nm}$ correspond to standard FA. ${ }^{17}$ Hence, the UV/Vis data indicate no structural changes of the SWCNTs and FA that could be related to the SWCNT-FA modification.

In a recent study, SWCNTs have been utilized as an effective quencher ${ }^{18}$ for a variety of dyes decreasing their fluorescence

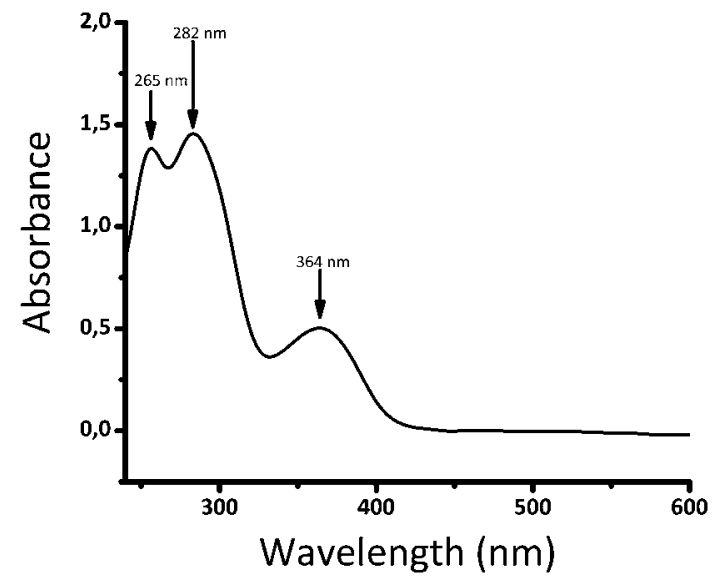

Fig. 2 UV-Vis spectrum of the FA-coated SWCNT solution. 
signals through electronic mechanisms. The fluorescence behavior of the SWCNT-FA conjugate was similar to the aforementioned observation. A comparison between the FA and SWCNT-FA fluorescence emission spectra is presented in Fig. 3. The observed quenching of the FA fluorescence was dependent on the SWCNTs and agreed well with the results previously presented. ${ }^{18}$

Raman scattering spectroscopy has been extensively utilized to study the vibrational modes of carbon nanotubes. ${ }^{11,19-22}$ In particular, vibrational spectra can provide useful insights into aggregation, dispersion and functionalization states of SWCNTs. ${ }^{11}$ In recent reports, ${ }^{11}$ authors analyzed the evolution of (i) the radial breathing modes (RBMs), (ii) the tangential D band, (iii) the disorder-induced $\mathrm{D}$ band, and (iv) the $\mathrm{G}$ band to investigate dispersion states and covalent functionalization of SWCNTs, and to map COOH groups on oxidized SWCNTs. Hence, inelastic scattering spectra can provide a more detailed picture of the vibrational states induced by the noncovalent FA coatings.

We start by analyzing the aggregation and dispersion states of SWCNTs. ${ }^{23}$ Fig. 4 shows the evolution of the RBM of the nonfunctionalized and FA-coated SWCNTs. The intensity of the $\mathrm{RBM}$ at $270 \mathrm{~cm}^{-1}$, also known as the roping peak, ${ }^{23,24}$ decreased after functionalization with FA. The intensity drop of the roping peak was evidence of a good dispersion, ${ }^{24}$ and the result verified the dual role of FA in the dispersion and functionalization of the SWCNTs. This can be further explained as a result of a low irregular distribution of $\mathrm{sp}^{3}$ sites due to the noncovalent functionalization that decreased the intensity of the so-called van Hove singularities. ${ }^{23}$

The functionalization and purity of the SWCNTs were evaluated by measuring the intensity ratio between the $\mathrm{D}$ and G-bands, i.e., $I_{\mathrm{D}} / I_{\mathrm{G}} \cdot{ }^{11,19,20,23}$ A value of $I_{\mathrm{D}} / I_{\mathrm{G}}=1$ usually indicates high quantities of structural defects on the surface of the SWCNTs. Fig. 5 displays vibrational changes induced by the noncovalent coating of FA on the SWCNTs. While the G-band is located near $1580 \mathrm{~cm}^{-1}$ and represents the tangential modes, the D-band is related to the induced disorder and is found at $1324 \mathrm{~cm}^{-1}$. The $I_{\mathrm{D}} / I_{\mathrm{G}}$ intensity ratios for the SWCNTs and the

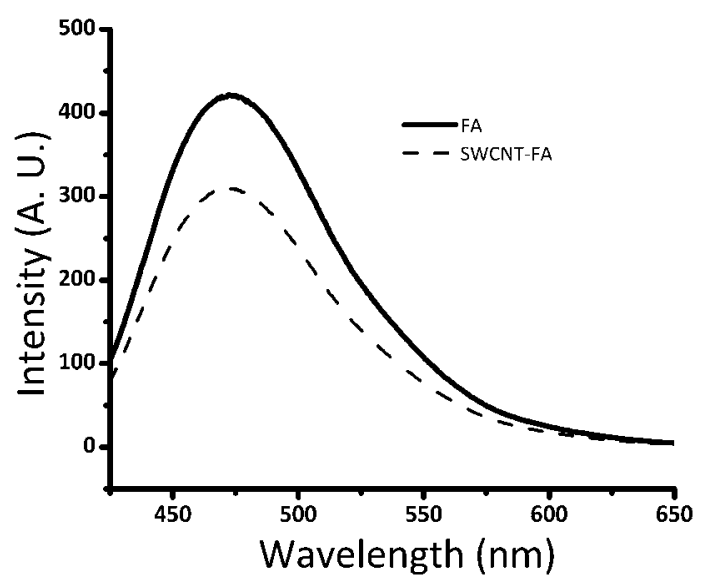

Fig. 3 Comparison of the fluorescence emission from the FA and the SWNT-FA conjugate.

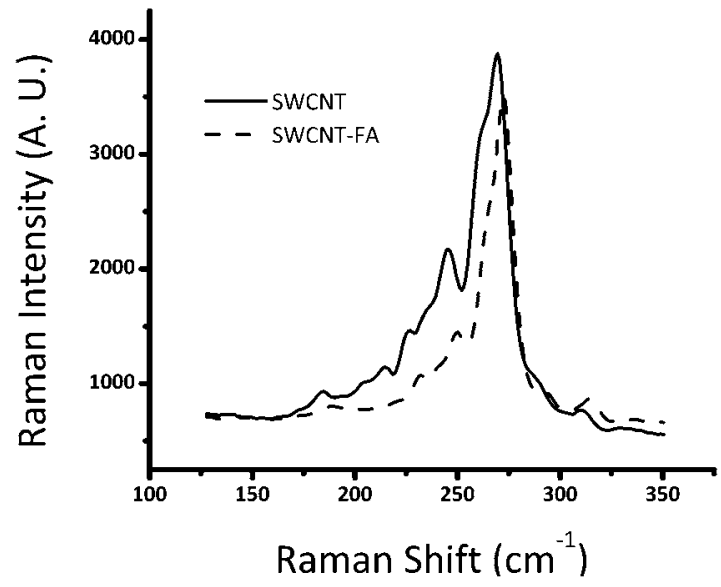

Fig. 4 The radial breathing modes of the SWCNTS and the SWCNT-FA conjugate.

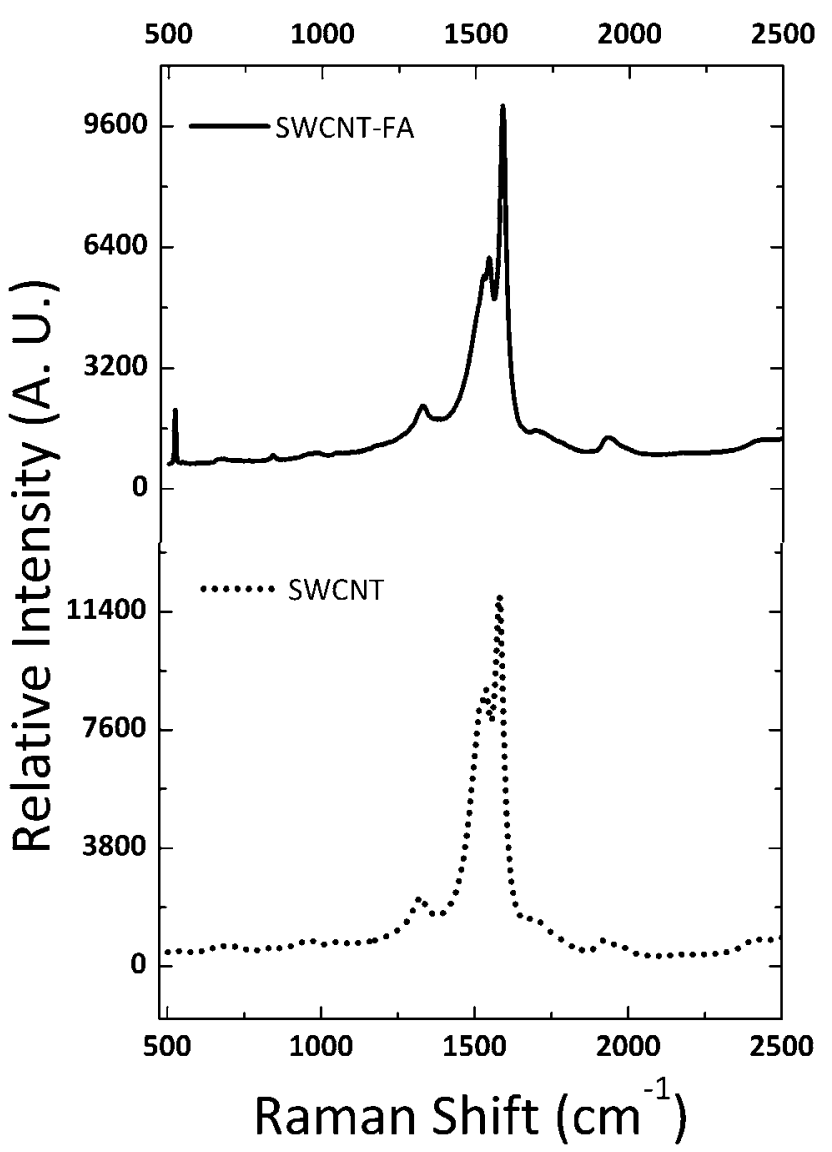

Fig. 5 Raman spectra of SWCNT (black line) and SWCNT-FA (red line) dispersions (laser $785 \mathrm{~nm}, 1 \mathrm{~mW}$ ).

FA-functionalized nanotube conjugates are listed in Table 1, and were found to be 0.186 and 0.217 , respectively. These relatively small variations of the $I_{\mathrm{D}} / I_{\mathrm{G}}$ ratios can be interpreted as an indication of a noncovalent interaction character between FA and carbon nanotubes that inhibits the formation of large structural defects. Covalent functionalizations, on the other hand, produce significantly larger defects on the surface of the SWCNTs. ${ }^{23}$ 
Table 1 Peak positions of RBM, D, and G bands for SWCNT and SWCNT-FA dispersions as well as D/G ratios from the Raman spectra with a $785 \mathrm{~nm}$ excitation laser

\begin{tabular}{|c|c|c|c|c|}
\hline \multirow[b]{2}{*}{ Sample } & \multicolumn{3}{|c|}{ Raman shift $\left(\mathrm{cm}^{-1}\right)$} & \multirow{2}{*}{$\begin{array}{l}\text { Intensity } \\
\text { ratio } \\
\mathrm{D} / \mathrm{G}\end{array}$} \\
\hline & RBM & $\mathrm{D}$ & G & \\
\hline SWCNT & 269 & 1325 & 1580 & 0.186 \\
\hline SWCNT-FA & 271 & 1328 & 1587 & 0.217 \\
\hline
\end{tabular}

The $\mathrm{D} / \mathrm{G}$ intensity ratio varied slightly, indicating that the immobilization occurred through a noncovalent interaction; a covalent functionalization would have significantly increased the D/G ratios. Raman spectroscopy was evidence of the presence of structural defects on the surface of the nanotubes due to the binding of FA.

The conjugate between SWCNTs and FA was studied through a computational hybrid method: our own N-layered Integrated Orbital and molecular mechanics (B3LYP(6-31G(d):UFF)). Computational studies on the electronic structure of FA and SWCNTs were done before and after interaction with a basis set 6-31G(d). Obtained results confirmed that the interaction occurs via hydrogen bonding between protons of the glutamic moiety from FA and $\pi$ electrons from carbon nanotubes.

Finally, SEM and EDX techniques were utilized to obtain structural information of the functionalized SWCNTs at the nanoscale. Fig. 6 shows a SEM image together with an EDX spectrum of the FA-functionalized SWCNTs. The SEM inset shows debundled, individual carbon nanotubes.

The presence of FA on the SWCNTs was confirmed using the EDX technique. Elemental peaks of $\mathrm{N}$ and $\mathrm{O}$ on the horizontal axis corresponded to the FA compound. The Na peak in the spectra was expected and was attributed to $\mathrm{NaOH}$ that was used in the solubilization step of FA. In the spectra of the SWCNT without the FA coating (not shown), the elemental peak of $\mathrm{N}$ was not observed.

In the final step, we determined the distribution of length and diameters in an array of the FA-functionalized SWCNTs. ${ }^{25}$ Fig. 7 shows a topographical $3 \times 3 \mu \mathrm{m}$ image of the FA-coated SWCNTs. The protrusions observed on the SWCNTs indicate the presence of FA around the carbon nanostructure.

The cytotoxicity of SWCNT-FA was investigated using MTT assay which has been described as a very suitable method for the detection of nanoparticle toxicity. ${ }^{26}$

The published data about toxicity of carbon nanotubes are inconsistent and widely disputed especially those using MTT assay. ${ }^{27}$ CNTs can produce errors in the interpretation of results due to the interferences presented with formazan after reduction of MTT by mitochondrial enzymes. ${ }^{28}$ Recent studies have reported a threshold concentration on the nanotube cytotoxicity in the range of $10-50 \mu \mathrm{g} \mathrm{mL}{ }^{-1} \cdot{ }^{14}$ In our current work SWCNTs were highly soluble in water after functionalization with the biocompatible molecule FA. As is shown in Table 2 at the highest concentration tested (335 $\left.\mu \mathrm{g} \mathrm{mL}^{-1}\right)$, SWCNT-FA conjugates were not toxic in THP-1 cells.

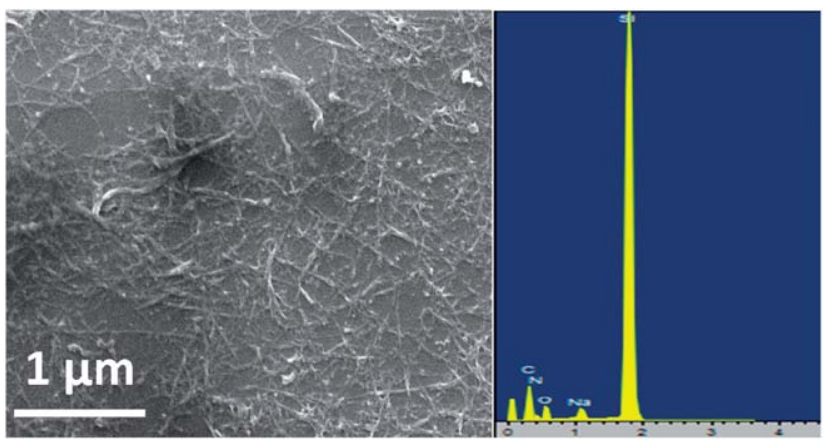

Fig. 6 Representative SEM image and the EDX spectrum of the SWCNT-FA conjugate.
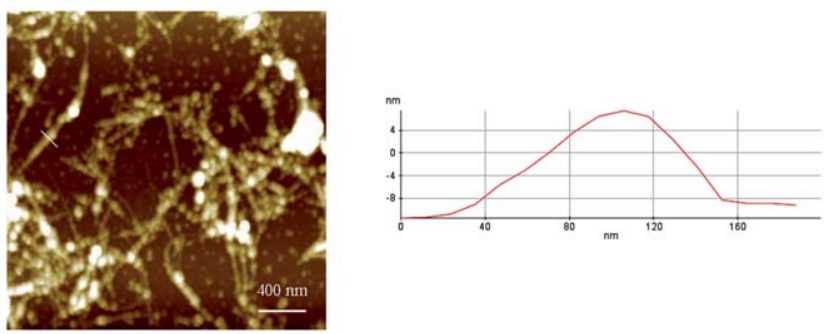

Fig. 7 Topographic image of FA-coated SWCNTs on the silicon substrate using non-contact mode imaging.

Table 2 Cytotoxicity of SWCNT-FA in THP-1 cells

\begin{tabular}{lll}
\hline & \multicolumn{1}{c}{ CC50 } & \\
\cline { 2 - 2 } & DS & CC90 \\
\hline SWCNT-FA $\left(\mu \mathrm{m} \mathrm{mL}^{-1}\right)$ & $>335$ & DS \\
Miltefosine $(\mu \mathrm{M})$ & $50.88 \pm 11.61$ & $>335$ \\
& & $>200$
\end{tabular}

The ability of the SWCNT-FA conjugate to internalize inside THP-1 cells was evaluated by light microscopy images. As is shown in Fig. 8 after incubation of SWCNT-FA for 24 h, accumulation was clearly observed in the cytoplasm of the cells and dispersion of nanotubes was not observed on the cellular structure.

Internalization of the SWCNT covalently functionalized with FA in Hep-G2 has been observed after $1 \mathrm{~h}$ of incubation. ${ }^{\mathbf{1 4}}$ However accumulation of SWCNT-FA in the cytoplasm has not been reported, this accumulation in our results could be due probably to the formation of protrusions on the wall of the nanotubes (see Fig. 7) thus producing conglomerates of the SWCNT bound by FA. The fact that FA is immobilized on a nanostructure such as a SWCNT does not influence the FR binding ability to interact with FA. A previous study involving FA-functionalized peptide nanotubes aimed to interact with HeLa cells for the development of an electrochemical biosensor showed the efficiency and selectivity of the FR over-expressed in HeLa cells to bind FA-functionalized peptide nanotubes. ${ }^{29}$

As is shown in Fig. 8 and 9 the internalization percentage increases until $48 \mathrm{~h}$ of incubation. After $72 \mathrm{~h}$ of incubation the \%internalization decreases by less than $10 \%$ for the three 

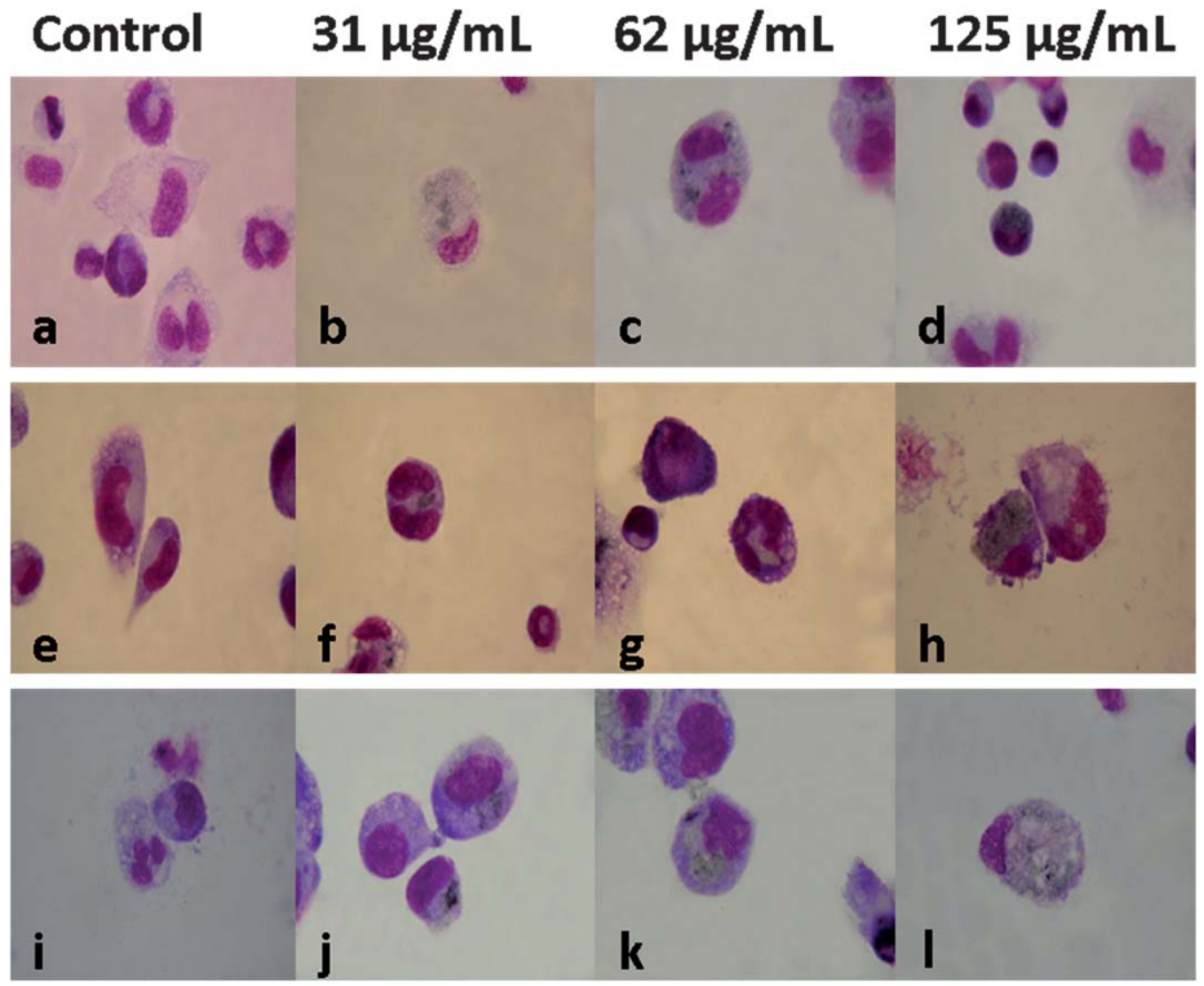

Fig. 8 Internalization of SWCNT-FA in THP-1 cells. (a-d) 24 h; (e-h) 48 h; (i-l) 72 h of incubation.

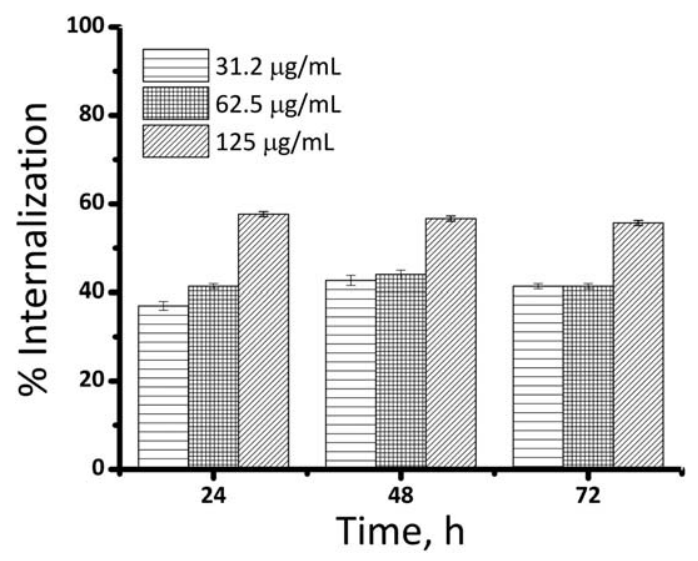

Fig. 9 Internalization percentage of SWCNT-FA in THP-1 cells.

concentrations assayed. At 24 and $48 \mathrm{~h}$ of incubation the \% internalization of SWCNT-FA increased with the concentration of the nanotubes. Therefore, more SWCNT-FA were internalized as more were added to THP- 1 cells. This concentrationdependent cellular internalization was observed in other works. ${ }^{14,30}$

Finally, control experiments using a FR negative cell line were performed in order to show the selectivity of the SWCNTFA conjugate towards FR receptors. For this, Vero cells (ATCC) which are cells isolated from the kidney of an African green monkey and do not over-express folate receptors were used. The obtained results displayed in Fig. S1 $\nmid$ show that SWCNT-FA conjugates were not present inside Vero cells due to the absence of FR needed to interact with the FA immobilized on the SWCNT surface (ESI $\dagger$ ).

\section{Conclusions}

We have shown that FA could be attached to SWCNTs without covalent chemical functionalization. The SWCNT-FA conjugate thus obtained was highly water-soluble, forming dark-colored solutions. Spectroscopic methods show that FA was intimately associated with the nanotubes. According to SEM and AFM images, FA was wrapped around the walls of the SWCNTs, which was evidence of a noncovalent functionalization. The FA functionalized SWCNTs were internalized by THP-1 cells demonstrating the successful interaction between the folic acid and the folate receptors over-expressed in the cells. This provides new insights into biomedical applications of carbon nanotubes. These functionalized nanostructures could be used to interact with other types of cells over-expressing folate receptors as in the case of cells infected with parasites responsible for tropical diseases such as leishmaniasis.

\section{Acknowledgements}

The Colombian Administrative Department of Science, Technology and Innovation, COLCIENCIAS, (Project 110245921468) 
and the Danish Agency for Science Technology and Innovation (FSS 09-066053) are gratefully acknowledged for financial support.

\section{Notes and references}

1 S. Iijima, Nature, 1991, 354, 56-58.

2 W. J. Huang, S. Taylor, K. F. Fu, Y. Lin, D. H. Zhang, T. W. Hanks, A. M. Rao and Y. P. Sun, Nano Lett., 2002, 2, 311-314.

3 N. W. S. Kam, M. O'Connell, J. A. Wisdom and H. J. Dai, Proc. Natl. Acad. Sci. U. S. A., 2005, 102, 11600-11605.

4 M. Shim, N. W. S. Kam, R. J. Chen, Y. M. Li and H. J. Dai, Nano Lett., 2002, 2, 285-288.

5 Z. Y. Zhao, P. A. Banerjee and H. Matsui, J. Am. Chem. Soc., 2005, 127, 8930-8931.

6 K. Balasubramanian and M. Burghard, Small, 2005, 1, 180192.

7 B. K. Price and J. M. Tour, J. Am. Chem. Soc., 2006, 128, 12899-12904.

8 P. Singh, S. Campidelli, S. Giordani, D. Bonifazi, A. Bianco and M. Prato, Chem. Soc. Rev., 2009, 38, 2214-2230.

9 D. A. Britz and A. N. Khlobystov, Chem. Soc. Rev., 2006, 35, 637-659.

10 J. U. Lee, J. Huh, K. H. Kim, C. Park and W. H. Jo, Carbon, 2007, 45, 1051-1057.

11 B. Koh, J. B. Park, X. M. Hou and W. Cheng, J. Phys. Chem. B, 2011, 115, 2627-2633.

12 A. Star and J. F. Stoddart, Macromolecules, 2002, 35, 75167520 .

13 A. Star, Y. Liu, K. Grant, L. Ridvan, J. F. Stoddart, D. W. Steuerman, M. R. Diehl, A. Boukai and J. R. Heath, Macromolecules, 2003, 36, 553-560.

14 B. Kang, D. C. Yu, S. Q. Chang, D. Chen, Y. D. Dai and Y. T. Ding, Nanotechnology, 2008, 19, 375103.

15 S. J. Yang, F. H. Lin, K. C. Tsai, M. F. Wei, H. M. Tsai, J. M. Wong and M. J. Shieh, Bioconjugate Chem., 2010, 21, 679-689.
16 S. H. Jeong, K. K. Kim, S. J. Jeong, K. H. An, S. H. Lee and Y. H. Lee, Synth. Met., 2007, 157, 570-574.

17 J. J. Castillo, M. H. Torres, D. R. Molina, J. Castillo-Leon, W. E. Svendsen, P. Escobar and F. Martinez, Carbon, 2012, 50, 2691-2697.

18 E. S. Cho, S. W. Hong and W. H. Jo, Macromol. Rapid Commun., 2008, 29, 1798-1803.

19 P. T. Araujo, P. B. C. Pesce, M. S. Dresselhaus, K. Sato, R. Saito and A. Jorio, Phys. E., 2010, 42, 1251-1261.

20 D. W. Horn, K. Tracy, C. J. Easley and V. A. Davis, J. Phys. Chem. C, 2012, 116, 10341-10348.

21 J. Y. Mevellec, C. Bergeret, J. Cousseau, J. P. Buisson, C. P. Ewels and S. Lefrant, J. Am. Chem. Soc., 2011, 133, 16938-16946.

22 V. Mussi, C. Biale, S. Visentin, N. Barbero, M. Rocchia and U. Valbusa, Carbon, 2010, 48, 3391-3398.

23 D. Yoon, J. B. Choi, C. S. Han, Y. J. Kim and S. Baik, Carbon, 2008, 46, 1530-1534.

24 L. Carson, C. Kelly-Brown, M. Stewart, A. Oki, G. Regisford, Z. P. Luo and V. I. Bakhmutov, Mater. Lett., 2009, 63, 617620.

25 C. Lamprecht, J. Danzberger, P. Lukanov, C. M. Tiilmaciu, A. M. Galibert, B. Soula, E. Flahaut, H. J. Gruber, P. Hinterdorfer, A. Ebner and F. Kienberger, Ultramicroscopy, 2009, 109, 899-906.

26 Y. Y. Wan, H. L. Zhao, R. H. Yu and M. B. Lan, J. Nanosci. Nanotechnol., 2012, 12, 2456-2461.

27 D. X. Cui, F. R. Tian, C. S. Ozkan, M. Wang and H. J. Gao, Toxicol. Lett., 2005, 155, 73-85.

28 J. M. Worle-Knirsch, K. Pulskamp and H. F. Krug, Nano Lett., 2006, 6, 1261-1268.

29 J. J. Castillo, W. E. Svendsen, N. Rozlosnik, P. Escobar, F. Martinez and J. Castillo-Leon, Analyst, 2013, 138, 10261031.

30 L. Lacerda, G. Pastorin, D. Gathercole, J. Buddle, M. Prato, A. Bianco and K. Kostarelos, Adv. Mater., 2007, 19, 14801484 . 


\section{Non-covalent conjugate of single-walled carbon nanotubes and folic acid for interaction with cells over-expressing folate receptors}

John J. Castillo ${ }^{\mathrm{a}}$, Tomas Rindzevicius ${ }^{\mathrm{b}}$, Leidy V. Novoa ${ }^{\mathrm{c}}$, Winnie E. Svendsen ${ }^{\mathrm{b}}$, Noemi Rozlosnik $^{\mathrm{b}}$, Anja Boisen ${ }^{\mathrm{b}}$, Patricia Escobar ${ }^{\mathrm{c}}$, Fernando Martínez O. ${ }^{\mathrm{a}}$, Jaime Castillo-León ${ }^{\mathrm{b}^{*}}$

a Centro de Investigaciones en Catálisis, Universidad Industrial de Santander, Sede Guatiguará UIS Km 2 vía Refugio, Piedecuesta, Colombia

${ }^{b}$ Department of Micro- and Nanotechnology, Technical University of Denmark, Lyngby 2800, Denmark, Tel: +45 4525 6837; E-mail: jaic@ @anotech.dtu.dk

c Centro de Investigaciones en Enfermedades Tropicales, Universidad Industrial de Santander, Sede Guatiguará UIS Km 2 vía Refugio, Piedecuesta, Colombia

Interaction of SWCNT-FA with a folate receptors negative cell line

For this experiment Vero cells (ATCC) which are cells isolated from the kidney of an African green monkey and do not over-express folate receptors were used. Vero cells were maintained in culture medium 1640 (Gibco) supplemented with $5 \%$ to $\mathrm{SBFI} 37^{\circ} \mathrm{C}, 5 \% \mathrm{CO}_{2}$ and $95 \%$ humidity and were incubated with SWCNT-FA with a concentration of $0.25 \mathrm{mg} / \mathrm{mL}$ during a period of 24,48 and 72 hours.

\section{control}

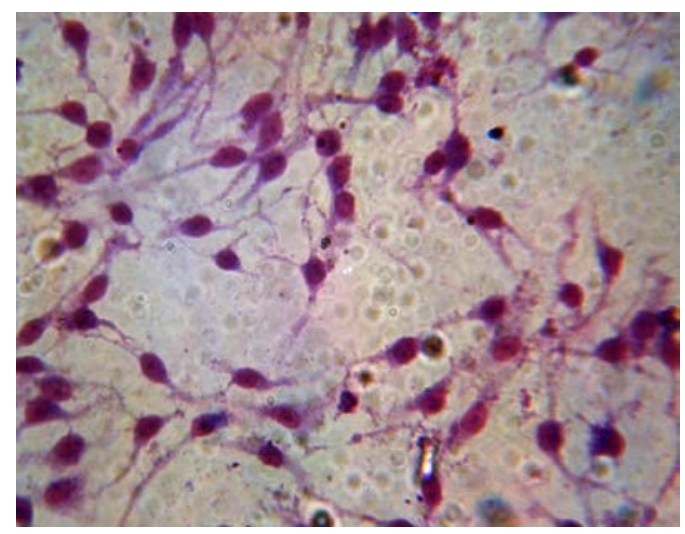

48 hours

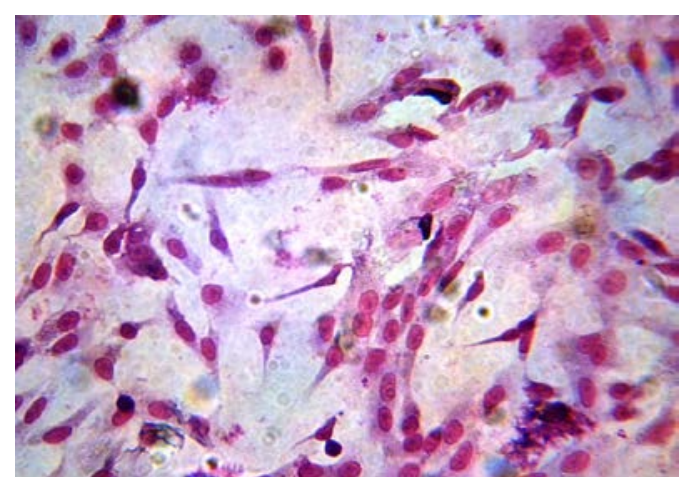

24 hours

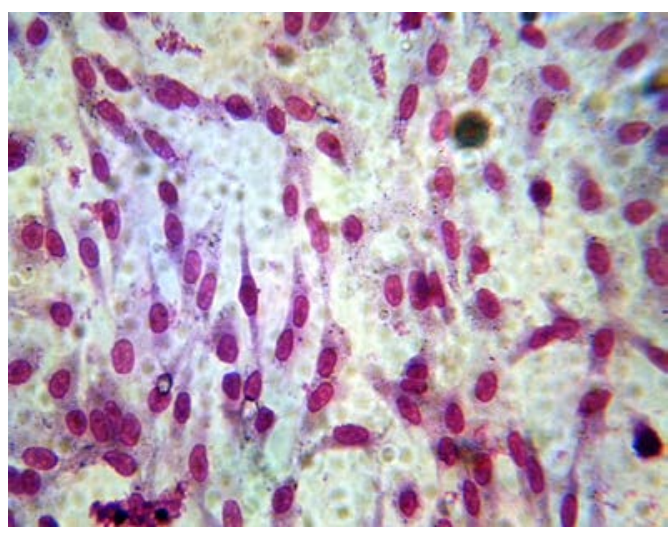

72 hours

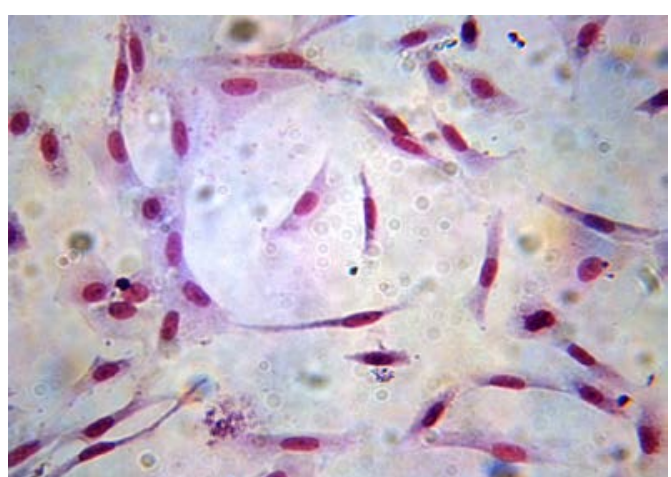

Figure S1. Interaction of SWCNT-FA with Vero cells a FR negative cell line. No SWCNT-FA was observed inside Vero cells. 